\title{
Inhibition of Brass Corrosion in Acid Medium Using Thiazoles
}

\author{
K. K. Taha*, M. E. Mohamed, S. A. Khalil, S. A. Talab \\ Department of Chemistry \& Industrial Chemistry, College of Appl. Sci., University of Bahri, Sudan \\ E-mail address: kamaltha1012@yahoo.com
}

\begin{abstract}
Brass as an alloy composed mainly of copper is great industrial uses such as heat exchangers and similar other facility due to its good thermal properties. Due to the presence of the considerable ratio of zinc the alloy suffers from zinc dissolution or dezincification. Dezincification rate increases with the increase in the ratio of zinc in the alloy. In this study benzothiazole (BTH) and its substituent's 2-methylbenzothiazole (MeBTH), 2-aminobenzothiazole (ABTH), 2mercaptobenzothiazole (MBTH) and 2-phenylbenzothiazole (PhBTH) have been used as corrosion inhibitors for $\alpha$-brass in stirred $0.1 \mathrm{M} \mathrm{HClO}_{4}$. The methods of investigation include weight loss, Tafel and linear polarizations and electrochemical impedance spectroscopy. The order of inhibition efficiency ( $\%$ E) was calculated and the values obtained has indicated the sequence of inhibition efficiency was found to be BTH $<\mathrm{MeBTH}<\mathrm{ABTH}<\mathrm{PhBTH}<\mathrm{MBTH}$. The calculated values of thermodynamic parameters support this order. The inhibitors were found to suppress the corrosion rate by the formation of films which were identified by IR, SEM and EDAX techniques.
\end{abstract}

Keywords: Benzothiazoles; Brass Corrosion Inhibitors; Perchloric Acid

\section{INTRODUCTION}

Copper and its alloys as non-ferrous alloys are used in industrial facilities like heat exchangers due to their good thermal and electrical properties. As the percentage of zinc increases brass alloys are subject to zinc leaching or zincification [1]. Vinicius et al. [2] attributed the low corrosion resistance of brass alloy to a non-protective anodic layer structure consisting of a complex $\mathrm{ZnO} \cdot \mathrm{xH}_{2} \mathrm{O} / \mathrm{Cu}_{2} \mathrm{O}-\mathrm{CuO}$. Organic compounds are used as inhibitors due to the presence of a hetero-atoms acting as an active center for adsorption on the metallic surface [3]. The use of benzothiazoles as corrosion inhibitors for steel [4-9], copper [10-14], and brass [15] has been studied in different media. Studies their use as corrosion of zinc are sparse [16]. 4-phenylthiazole derivatives were used to prevent dezincification of $\alpha$-brass in acid chloride solution [17]. The use of thiazoles as corrosion inhibitors in the powerful oxidizing agent perchloric acid [18] has not been reported in literature. 
In the acidic medium benzothiazole and substituted benzothiazoles are protonated at nitrogen atom and subsequently get chemisorbed on the surface of brass through coordinate type of bond involving the lone pair of electrons on the heteroatoms of the thiazole moiety [19]. In this study the inhibitor efficiency with a series of compounds chosen is calculated by different methods and the values obtained are related to the molecular structure. Benzothiazole and substituted bezothiazoles have been used as corrosion inhibitors in order to study the effect of substituent's. In this connection many of the criteria support the adsorption of these inhibitors on brass surface.

\section{MATERIALS AND METHODS}

\section{1. Chemicals and Sample Preparation}

Benzothiazole (BTH), 2-methylbenzothiazole (MeBTH), 2-aminobenzothiazole $(\mathrm{ABTH}), 2$-phenylbenzothiazole $(\mathrm{PhBTH})$ and 2-mercaptobenzothiazole (MBTH) (Merck Germany) were obtained from used without purification and freshly distilled double distilled water were used. A piece of (70/30) brass was cut in the form of a disk and fitted in Tygon tubing leaving about $0.31 \mathrm{~cm}^{2}$ surface area exposed to the corrosive medium. The brass electrode was polished successively on 200 and 400 emery papers, washed in running tap water, rinsed in distilled water before exposure to stirred $0.1 \mathrm{M} \mathrm{HClO}_{4}$ and stirred $0.1 \mathrm{M}$ $\mathrm{HClO}_{4}$ containing $0.01 \mathrm{M}$ of each inhibitor.

\section{2. Weight loss measurements}

The weight loss data was acquired by spectrophotometric estimation of $\mathrm{Cu}$ and $\mathrm{Zn}$ in the solution after two hours of immersion time for the brass electrode. The $\% E=\left[\left(\mathrm{w}_{0}-\mathrm{w}\right) / \mathrm{w}_{0}\right]$ $\mathrm{x} 100$, where $\mathrm{w}_{0}$ and $\mathrm{w}$ corrosion rates in absence and presence of inhibitors. The thermodynamic study was carried out using weight loss at different temperatures.

\section{3. Electrochemical study}

The polarization (Tafel and linear) experiments were carried out using TACUSSEL Potentiostat PR T(10-0.5) driven by a Function generator (GSTP-3) made by TACUSSEL (France). The potential was polarized in the anodic then the cathodic directions and the $\% \mathrm{E}=$ $\left[\left(i_{\text {corr' }}-i_{\text {corr }}\right) / i_{\text {corr }}\right] \times 100$ where $i_{\text {corr' }}$ and $i_{\text {corr }}$ are corrosion currents in absence and presence of inhibitors. A three compartment cell with brass as working electrode, platinum foil and saturated calomel electrode as counter and reference electrodes respectively were used for polarization studies.

The a.c. impedance measurements were performed using an electrochemical system SI $1280 \mathrm{~B}$ (SOLARTRON UK) at corrosion potentials over a frequency range of $10 \mathrm{kHz}$ to 0.01 $\mathrm{Hz}$ with signal amplitude of $10 \mathrm{~Hz}$.

\section{4. Fourier Transformation Infrared Spectroscopy}

The FT-IR studies for the pure inhibitors and the scraping of their films formed on brass after 24 hours exposure were made in $\mathrm{KBr}$ pellet and subjected to IR studies using Nicolet Impact 400D, FT-IR spectrophotometer having $4 \mathrm{~cm}^{-1}$ resolution. 


\section{5. Surface characterization techniques}

The scanning electron micrographs of the polished brass and brass surface after exposure to $0.1 \mathrm{M} \mathrm{HClO}_{4}$ alone and $0.1 \mathrm{M} \mathrm{HClO}_{4}$ containing $0.01 \mathrm{M}$ of each inhibitor was taken using scanning electron microscope model JEOL JSM-5600LV interfaced to a computer and JSM software. The Energy Dispersive X-ray Analysis (EDAX) studies calibration was done with respect to $\mathrm{Co} \mathrm{K} \alpha=6.9254 \mathrm{keV}$ and $\mathrm{Co} \mathrm{L} \alpha=0.7763 \mathrm{keV}$.

\section{RESULTS AND DISCUSSION}

The corrosion rates $\left(\mathrm{mg} / \mathrm{cm}^{2} / \mathrm{hr}\right)$ for brass in stirred $\mathrm{M} \mathrm{HClO}_{4}$ and stirred $\mathrm{HClO}_{4}$ containing optimum concentrations of inhibitors (Table 1) revealed that there is a decrease in corrosion in presence of these compounds. All these bezothiazoles offer inhibition for brass corrosion and their inhibition efficiency ( $\%$ E) had increased for benzothiazoles containing functional groups. This may be attributed to the presence of $\boldsymbol{\Pi}$-electrons or heteroatoms [19].

Yurt and Mihrican [20] reported that heteratoms donate electrons to the d-orbitals of transition metals thus protect them against corrosion. On the other hand Quraishi et al. [21] attributed corrosion inhibition by organics to the adsorption. The order of inhibition efficiency $(\% \mathrm{E})$ is $\mathrm{MBTH}>\mathrm{PhBTH}>\mathrm{ABTH}>\mathrm{MeBTH}>\mathrm{BTH}$.

Table 1. Corrosion rates $\left(\mathrm{mg} / \mathrm{cm}^{2} / \mathrm{hr}\right)$ and inhibition efficiency $(\% \mathrm{E})$ for brass in stirred $\mathrm{HClO}_{4}$ and stirred $\mathrm{HClO}_{4}$ containing optimum concentrations of benzothiazoles.

\begin{tabular}{|c|c|c|}
\hline Medium & $\left(\mathbf{m g} / \mathbf{c m}^{2} / \mathbf{h r}\right)$ & \% E \\
\hline $0.1 \mathrm{M} \mathrm{HClO}_{4}$ & 0.758 & -- \\
\hline $0.1 \mathrm{M} \mathrm{HClO}_{4}+\mathrm{PhBTH}_{(0.0001 \mathrm{M})}$ & 0.105 & 86.0 \\
\hline $0.1 \mathrm{M} \mathrm{HClO}_{4}+\mathrm{MBTH}(0.001 \mathrm{M})$ & 0.108 & 85.6 \\
\hline $0.1 \mathrm{M} \mathrm{HClO}_{4}+\mathrm{ABTH}(0.01 \mathrm{M})$ & 0.148 & 80.3 \\
\hline $0.1 \mathrm{M} \mathrm{HClO}_{4}+\mathrm{MeBTH}(0.01 \mathrm{M})$ & 0.165 & 78.1 \\
\hline $0.1 \mathrm{M} \mathrm{HClO}_{4}+\mathrm{BTH}(0.01 \mathrm{M})$ & 0.396 & 47.3 \\
\hline
\end{tabular}

Figure 1 represents the polarization curves for brass in stirred $\mathrm{HClO}_{4}$ and stirred $\mathrm{HClO}_{4}$ containing optimum concentrations of inhibitors. The inhibitors shifted the corrosion potentials to noble direction. The $\% \mathrm{E}$ (Table 2) was found to be of the same order as weight loss results. 


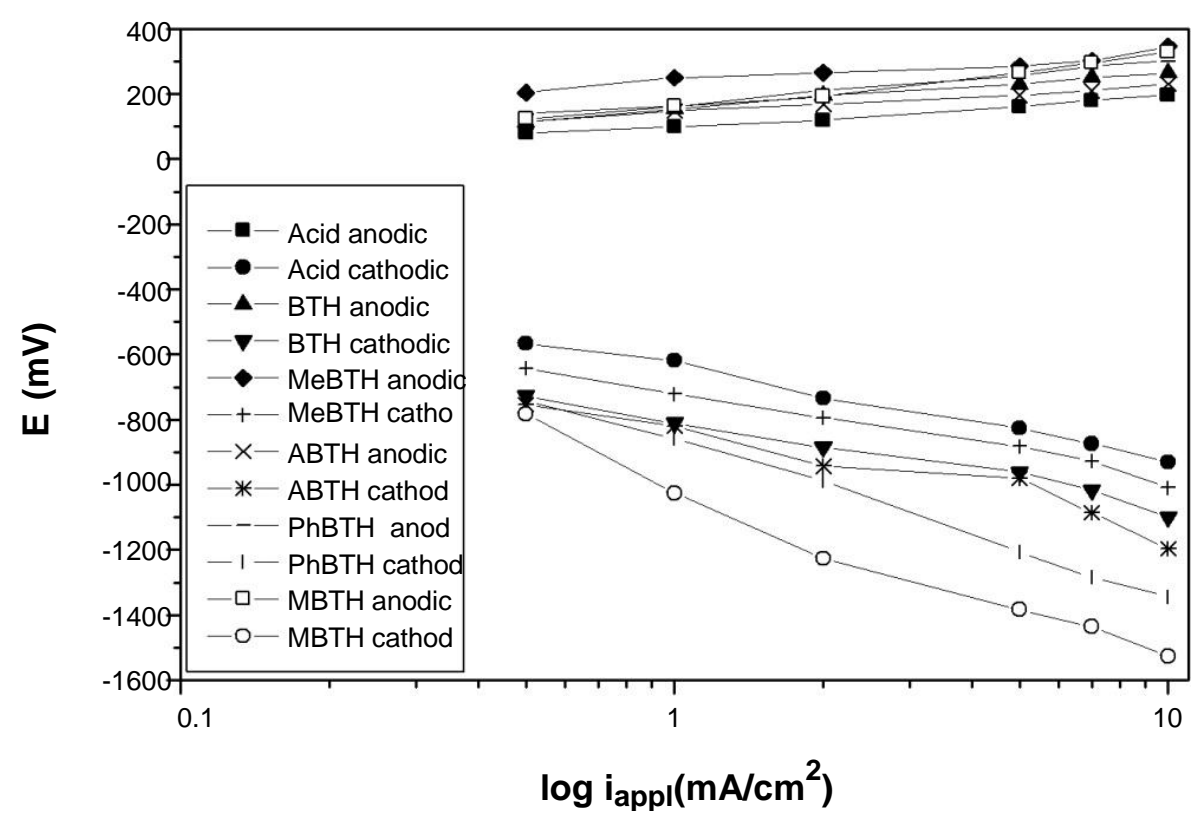

Fig. 1. Polarization curves for brass in stirred $0.1 \mathrm{M} \mathrm{HClO}_{4}$ and stirred $0.1 \mathrm{M} \mathrm{HClO}_{4}$ containing optimum concentrations of benzothiazoles.

Table 2. Values of corrosion potential $\left(\mathrm{E}_{\text {corr }}\right)$, corrosion current $\left(\mathrm{I}_{\text {corr }}\right)$, inhibition efficiency $(\% \mathrm{E})$ and Tafel slopes $\left(\beta_{\mathrm{a}}\right.$ and $\mathrm{B}_{\mathrm{c}}$ ) for brass sample in stirred $1 \mathrm{M} \mathrm{HClO}_{4}$ with and without inhibitors from Tafel extrapolation method

\begin{tabular}{|c|c|c|c|c|c|}
\hline Medium & $\mathbf{E}_{\mathbf{c o r r}}(\mathbf{m V})$ & $\boldsymbol{\beta}_{\mathbf{a}}$ & $\mathbf{B}_{\mathbf{c}}$ & $\mathbf{i}^{\mathbf{c o r r}}\left(\boldsymbol{\mu} \mathbf{A} / \mathbf{c m}^{2}\right)$ & $\boldsymbol{\%} \mathbf{E}$ \\
\hline $0.1 \mathrm{M} \mathrm{HClO}_{4}$ & -150 & 37 & 117 & 52 & - \\
\hline $0.1 \mathrm{M} \mathrm{HClO}_{4}+\mathrm{BTH}(0.01 \mathrm{M})$ & -110 & 50 & 139 & 16.6 & 68.0 \\
\hline $0.1 \mathrm{M} \mathrm{HClO}_{4}+\mathrm{MeBTH}(0.01 \mathrm{M})$ & -100 & 56 & 135 & 9.4 & 82.0 \\
\hline $0.1 \mathrm{M} \mathrm{HClO}_{4}+\mathrm{ABTH}(0.01 \mathrm{M})$ & -97 & 51 & 143 & 7.2 & 86.0 \\
\hline $0.1 \mathrm{M} \mathrm{HClO}_{4}+\mathrm{PhBTH}(0.0001 \mathrm{M})$ & -95 & 54 & 184 & 7.2 & 86.0 \\
\hline $0.1 \mathrm{M} \mathrm{HClO}_{4}+\mathrm{MBTH}(0.001 \mathrm{M})$ & -90 & 45 & 204 & 6.2 & 88.0 \\
\hline
\end{tabular}

In the polarization curve [Figure 1 and Table 2] the anodic and cathodic Tafel lines were shifted to higher potential values with the shift was greater in the cathodic region. This indicates that the inhibitors are mixed inhibitors [22,4] greatly blocking the cathodic sites and retard corrosion. The value of corrosion current (icorr) has decreased when inhibitors were added compared to the value in presence of the acid only. 


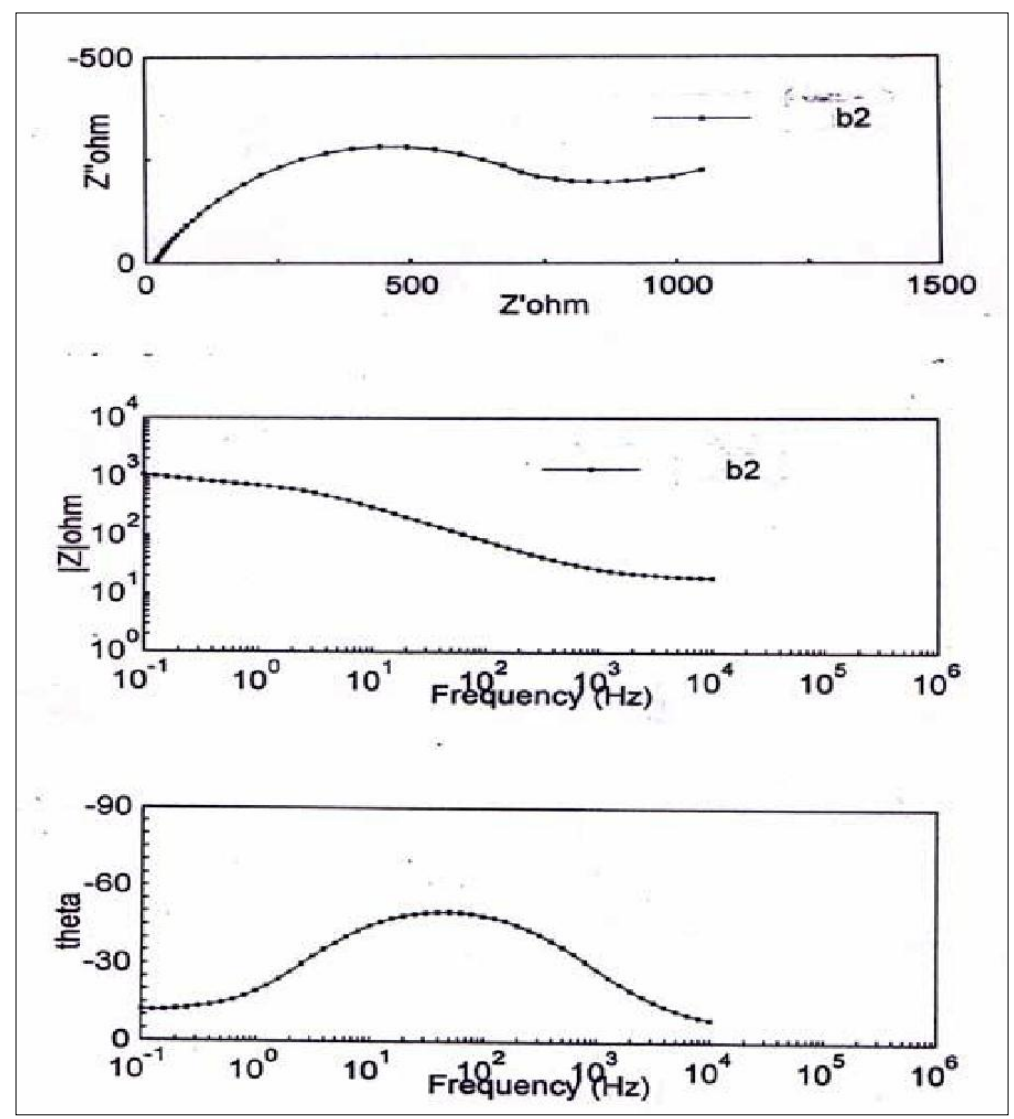

Fig. 2(a). Nyquist and Bode plots for brass in stirred $0.1 \mathrm{M} \mathrm{HClO}_{4}$.

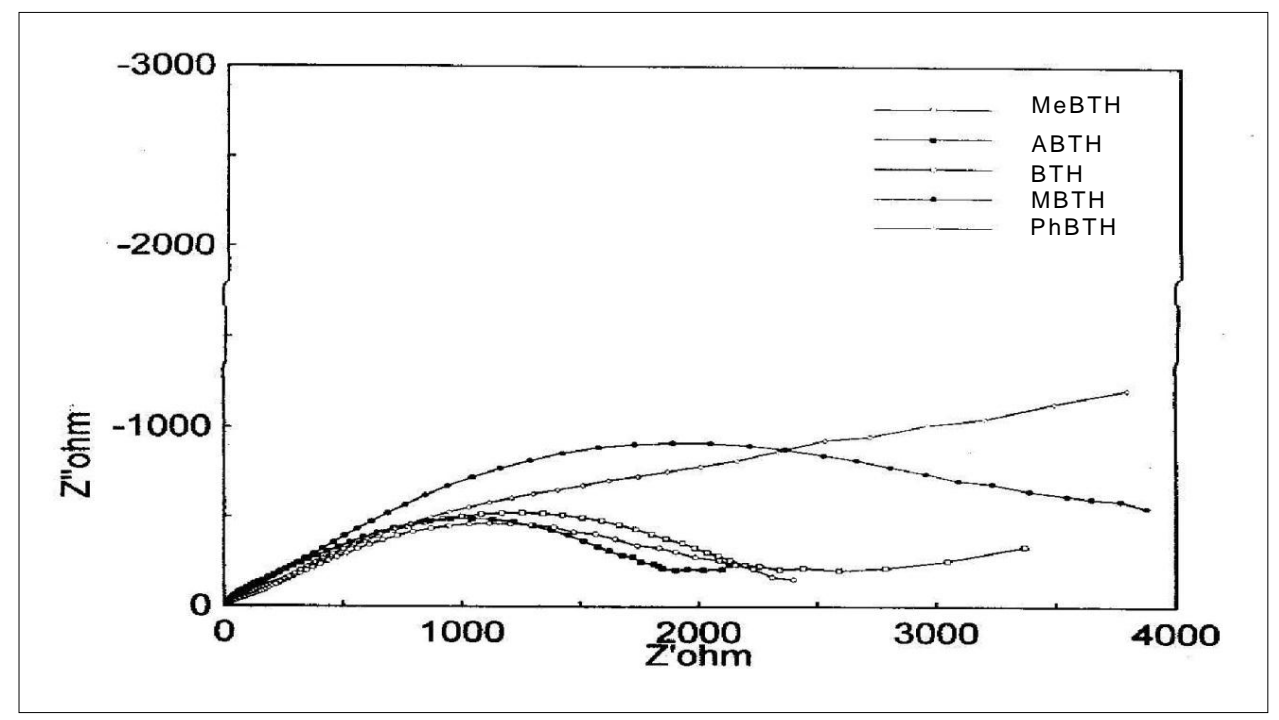

Fig. 2(b). Nyquist plots for brass in stirred $0.1 \mathrm{M} \mathrm{HClO}_{4}$ containing optimum concentrations of benzothiazoles. 


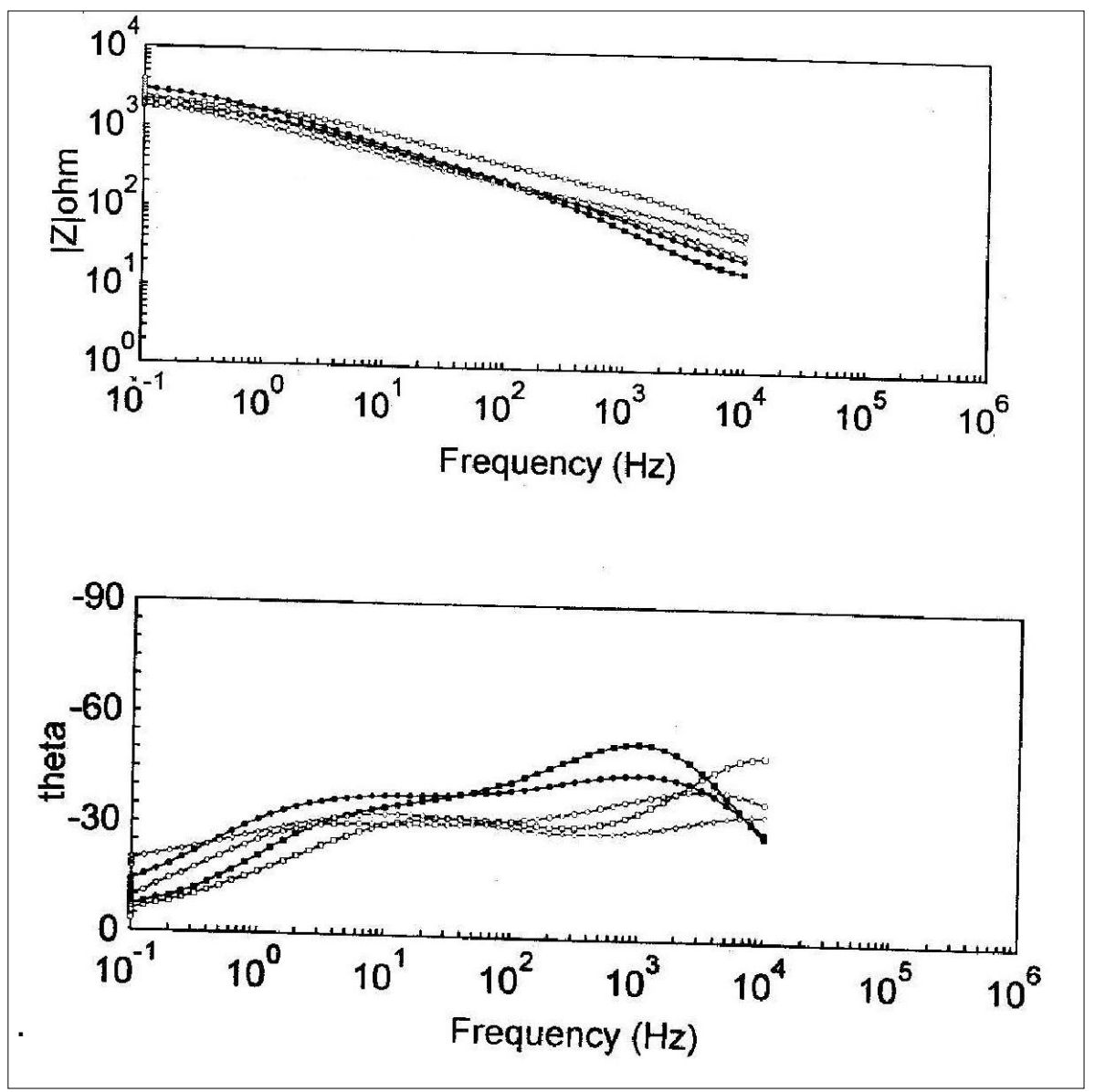

Fig. 2(c). Bode plots for brass in stirred $0.1 \mathrm{M} \mathrm{HClO}_{4}$ containing optimum concentrations of benzothiazoles.

This finding indicates that the corrosion is retarded the metal corrosion. The polarization resistance $(\mathrm{Rp})$ values obtained from the linear polarization were found to increase in presence of optimum concentration of inhibitors (Table 3 ).

The Tafel slopes values have changed for both anodic $\left(\boldsymbol{\beta}_{\mathbf{a}}\right)$ and cathodic $\left(\boldsymbol{\beta}_{\mathbf{c}}\right)$ polarization with greater change in the cathodic slopes. The change in Tafel slope is due to a change of dissolution mechanism due to inhibitors [23].

Using anodic and cathodic Tafel slopes obtained from Tafel line polarization $\mathbf{i}_{\text {corr }}$ was calculated using Stern-Geary equation [24]. The \% E was found to be MBTH $>$ PhBTH $>$ $\mathrm{ABTH}>\mathrm{MeBTH}>\mathrm{BTH}$.

Figures 2 (a-c), show the Nyquist and Bode plots for brass in $0.10 \mathrm{M} \mathrm{HClO}_{4}$ (Fig. $2 \mathrm{a}$ ) and brass in $0.10 \mathrm{M} \mathrm{HClO}_{4}$ containing thiazoles (Fig. $2 \mathrm{~b} \& \mathrm{c}$ ). Table (4) summarizes the electrochemical impedance results where the charge transfer resistance $\left({ }^{R}\right.$ ct) increased in presence of these inhibitors while double layer capacitance $\left({ }^{\mathrm{C}} \mathrm{dl}\right)$ values decreased. 
Table 3. Values of polarization resistance $\left(\mathrm{R}_{\mathrm{p}}\right)$, corrosion current $\left(\mathrm{I}_{\text {corr }}\right)$ and inhibition Efficiency $(\% \mathrm{E})$ for brass sample in stirred $0.1 \mathrm{M} \mathrm{HClO}_{4}$ and stirred $0.1 \mathrm{M} \mathrm{HClO}_{4}$ benzothiazoles from linear polarization.

\begin{tabular}{|c|c|c|c|}
\hline Medium & $\mathbf{R}_{\mathbf{p}}(\mathbf{\Omega})$ & corr $\left(\boldsymbol{\mu} \mathbf{A} / \mathbf{c m}^{2}\right)$ & $\boldsymbol{\%} \mathbf{E}$ \\
\hline $0.1 \mathrm{M} \mathrm{HClO}_{4}$ & 1000 & 38.6 & - \\
\hline $0.1 \mathrm{M} \mathrm{HClO}_{4}+\mathrm{BTH}(0.01 \mathrm{M})$ & 3800 & 13.6 & 64.8 \\
\hline $0.1 \mathrm{M} \mathrm{HClO}_{4}+\mathrm{MeBTH}(0.01 \mathrm{M})$ & 9380 & 5.9 & 84.7 \\
\hline $0.1 \mathrm{M} \mathrm{HClO}_{4}+\mathrm{ABTH}(0.01 \mathrm{M})$ & 10015 & 5.4 & 86.0 \\
\hline $0.1 \mathrm{M} \mathrm{HClO}_{4}+\mathrm{PhBTH}_{(0.0001 \mathrm{M})}$ & 29165 & 2.0 & 94.8 \\
\hline $0.1 \mathrm{M} \mathrm{HClO}_{4}+\mathrm{MBTH}(0.001 \mathrm{M})$ & 63650 & 0.8 & 97.9 \\
\hline
\end{tabular}

Table 4. Corrosion parameters for brass in $0.1 \mathrm{M} \mathrm{HClO}_{4}$ and containing benzothiazoles obtained from electrochemical impedance spectroscopy (EIS)

\begin{tabular}{|c|c|c|c|c|}
\hline Medium & ${ }^{R}$ ct $\Omega$ & $\begin{array}{c}\mathrm{C}_{\mathrm{dl}} \\
\left(\mu \mathrm{F} / \mathrm{cm}^{2}\right)\end{array}$ & $\begin{array}{c}\text { i corr } \\
\left(\mu \mathrm{A} / \mathrm{cm}^{2}\right)\end{array}$ & $\% \mathbf{E}$ \\
\hline $0.1 \mathrm{M} \mathrm{HClO}_{4}$ & 900 & 629 & 42.84 & - \\
\hline $0.1 \mathrm{M} \mathrm{HClO}_{4}+\mathrm{PhBTH}(0.0001 \mathrm{M})$ & 27843 & 304 & 2.10 & 95.1 \\
\hline $0.1 \mathrm{M} \mathrm{HClO}_{4}+\mathrm{MBTH}(0.001 \mathrm{M})$ & 7899 & 83 & 6.50 & 84.8 \\
\hline $0.1 \mathrm{M} \mathrm{HClO}_{4}+\mathrm{MeBTH}(0.01 \mathrm{M})$ & 7919 & 297 & 7.00 & 83.7 \\
\hline $0.1 \mathrm{M} \mathrm{HClO}_{4}+\mathrm{ABTH}(0.01 \mathrm{M})$ & 5523 & 91 & 9.50 & 77.8 \\
\hline $0.1 \mathrm{M} \mathrm{HClO}_{4}+\mathrm{BTH}(0.01 \mathrm{M})$ & 2592 & 45 & 19.80 & 53.8 \\
\hline
\end{tabular}

The double layer capacitance $(\mathrm{Cdl})$ and the frequency at which the imaginary component of the impedance is maximal (-Zmax) are found as represented in the equation:

$$
C_{d l}=\frac{1}{\omega \cdot R_{t}} \text { where } \omega=2 \pi \cdot f_{\max }
$$

The decrease in Cdl, which can result from a decrease in local dielectric constant and/or an increase in the thickness of the electrical double layer, suggests that the benzotriazole 
derivatives function by adsorption at the metal-solution interface, The decrease in the double layer capacitance may be due to a decrease in the dielectric constant or an increase in the double layer thickness as a result of adsorption $[25,26]$. The distortion in the semicircular behaviour in the Nyquist plots suggested an inhomogienity of the surface. It also suggests that the metal corrosion process is charge transfer control [12]. An appearance of an additional loop in Bode plots at higher frequencies is due to the formation of an adsorbed film on the surface $[27,28]$. In the thermodynamic study the $\% \mathrm{E}$ was considered as a measure of the extent of adsorption " $\theta$ ". Figure 3 shows $\log \theta$ vs $\log C$ plots for the adsorption of benzothiazoles on brass. Freundlich adsorption isotherms were found to be applicable as

$$
\log \theta=\log \mathrm{K}+\mathrm{n} \log \mathrm{C}
$$

The intercept " $K$ " was used to calculate the free energy of adsorption $\Delta \mathrm{G}_{\mathrm{a}}[29,30]$ using the equation

$$
K=\frac{1}{55.5} \exp \frac{\Delta G_{a}}{R T}
$$

where 55.5 is the concentration of water in the solution. The entropy of adsorption $\Delta \mathrm{S}_{\mathrm{a}}$ was obtained from the slope $\Delta \mathrm{G}_{\mathrm{a}}$ vs $\mathrm{T}$ plots. The enthalpy of adsorption $\left(\Delta \mathrm{H}_{\mathrm{a}}\right)$ was calculated using Gibbs-Helmholtz relation. The adsorption of inhibitor changes the structure of the double layer and the orientation of water molecules. The disorder in the double layer was found to be greater in presence of MBTH.

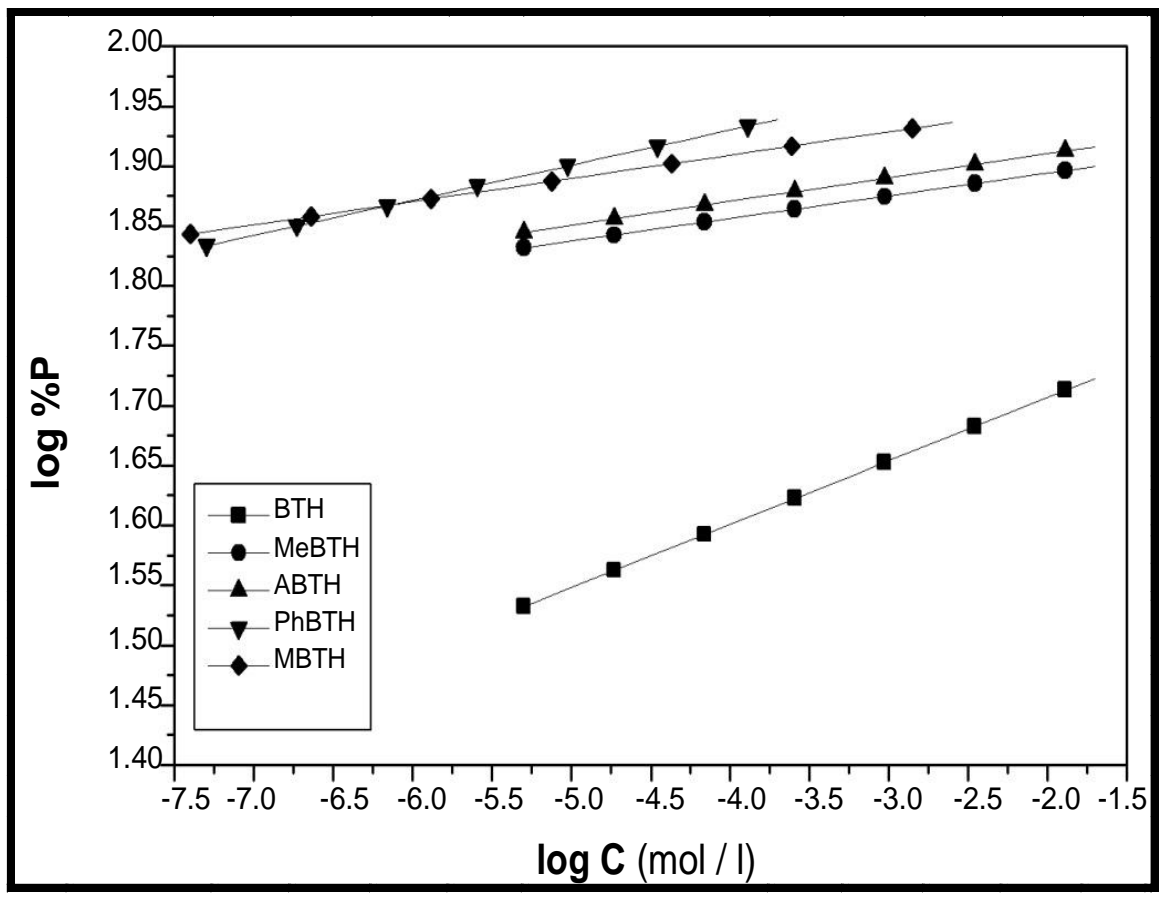

Fig. 3. Freundlich adsorption isotherm for benzothiazoles on brass. 
Table 5. Thermodynamic parameters obtained for brass in $0.1 \mathrm{M} \mathrm{HClO}_{4}$ containing optimum concentrations of bezothiazoles.

\begin{tabular}{|c|c|c|c|c|c|c|c|}
\hline Inhibitor & $\begin{array}{c}\text { Thermdynamic } \\
\text { parameters }\end{array}$ & $293 \mathrm{~K}$ & $303 K$ & $313 K$ & $323 \mathrm{~K}$ & $333 \mathrm{~K}$ & $343 K$ \\
\hline \multirow{3}{*}{$\begin{array}{l}\text { B } \\
T \\
H\end{array}$} & $\Delta \mathrm{G}_{\mathrm{a}} \mathrm{kJ} / \mathrm{mol}$ & -21.0 & -22.4 & -24.1 & -25.7 & -27.4 & -29.0 \\
\hline & $\Delta \mathrm{S}_{\mathrm{a}} \mathrm{J} / \mathrm{K} / \mathrm{mol}$ & 160 & & & & & \\
\hline & $\Delta \mathrm{H}_{\mathrm{a}} \mathrm{kJ} / \mathrm{mol}$ & 25.9 & 26.1 & 26.0 & 26.0 & 25.9 & 25.9 \\
\hline \multirow{3}{*}{$\begin{array}{c}\mathrm{Me} \\
\mathrm{B} \\
\mathbf{T} \\
\mathrm{H}\end{array}$} & $\Delta G_{a} \mathrm{~kJ} / \mathrm{mol}$ & -22.8 & -24.2 & -25.8 & -27.4 & -29.2 & -30.9 \\
\hline & $\Delta \mathrm{S}_{\mathrm{a}} \mathrm{J} / \mathrm{K} / \mathrm{mol}$ & 162 & & & & & \\
\hline & $\Delta \mathrm{H}_{\mathrm{a}} \mathrm{kJ} / \mathrm{mol}$ & 24.7 & 24.9 & 24.92 & 24.9 & 24.7 & 25.2 \\
\hline \multirow{3}{*}{$\begin{array}{l}\text { A } \\
\text { B } \\
Z \\
\text { L }\end{array}$} & $\Delta \mathrm{G}_{\mathrm{a}} \mathrm{kJ} / \mathrm{mol}$ & -25.2 & -27.1 & -29.3 & -31.61 & -34.3 & -37.1 \\
\hline & $\Delta \mathrm{S}_{\mathrm{a}} \mathrm{J} / \mathrm{K} / \mathrm{mol}$ & 210 & & & & & \\
\hline & $\Delta \mathrm{H}_{\mathrm{a}} \mathrm{kJ} / \mathrm{mol}$ & 36.2 & 36.5 & 36.4 & 36.22 & 35.6 & 34.9 \\
\hline \multirow{3}{*}{$\begin{array}{c}\mathrm{Ph} \\
\mathrm{B} \\
\mathbf{T} \\
\mathrm{H}\end{array}$} & $\Delta \mathrm{G}_{\mathrm{a}} \mathrm{kJ} / \mathrm{mol}$ & -33.4 & -34.0 & -35.3 & -36.22 & -37.2 & -38.1 \\
\hline & $\Delta \mathrm{S}_{\mathrm{a}} \mathrm{J} / \mathrm{K} / \mathrm{mol}$ & 190 & & & & & \\
\hline & $\Delta \mathrm{H}_{\mathrm{a}} \mathrm{kJ} / \mathrm{mol}$ & 22.3 & 25.5 & 24.2 & 25.15 & 26.1 & 27.1 \\
\hline \multirow{3}{*}{$\begin{array}{l}\mathbf{M} \\
\mathbf{B} \\
\mathbf{T} \\
\mathbf{H}\end{array}$} & $\Delta \mathrm{G}_{\mathrm{a}} \mathrm{kJ} / \mathrm{mol}$ & -29.0 & -31.3 & -35.0 & -38.90 & -42.1 & -46.1 \\
\hline & $\Delta \mathrm{S}_{\mathrm{a}} \mathrm{J} / \mathrm{K} / \mathrm{mol}$ & 238 & & & & & \\
\hline & $\Delta \mathrm{H}_{\mathrm{a} \mathrm{kJ}} / \mathrm{mol}$ & 40.7 & 40.1 & 39.5 & 38.0 & 37.1 & 35.6 \\
\hline
\end{tabular}

The $\Delta \mathrm{G}_{\mathrm{a}}$ of inhibitors is found to be in the range of $20-30 \mathrm{~kJ} / \mathrm{mol}$ (Table 5). The large negative value of $\Delta \mathrm{G}_{\mathrm{a}}$ is an indication of spontaneous strong interaction. The structural changes in inhibitor molecules upon adsorption lead to increased electron density at the adsorption site.

Table 6. IR spectral data for PhBTH \& MBTH and their films on brass.

\begin{tabular}{|c|c|c|c|c|c|}
\hline PhBTH & PhBTH+Brass & & MBTH & PhBTH+Brass & \\
\hline 3441 & 3436 & $v \mathrm{NH}$ & 3111 & 3436 & $v \mathrm{NH}$ \\
\hline 3069 & - & $v \mathrm{CH}$ & 3085 & - & $v \mathrm{CH}$ \\
\hline 3022 & & $v \mathrm{CH}$ & 3038 & & $v \mathrm{CH}$ \\
\hline 2919 & 2934 & $v \mathrm{CH}$ & 2961 & 2934 & $v \mathrm{CH}$ \\
\hline 2857 & 2852 & $v \mathrm{CH}$ & 2874 & 2852 & $v \mathrm{CH}$ \\
\hline 1564 & 1584 & $v \mathrm{C}=\mathrm{N}$ Thioamide I & 2832 & 1584 & $v \mathrm{C}=\mathrm{N}$ Thioamide $\mathrm{I}$ \\
\hline 1455 & 1424 & $v$ ring & 1608 & 1424 & $v$ ring \\
\hline 1331 & & $v$ C-N Thioamide II & 1499 & & $v$ C-N Thioamide II \\
\hline 1160 & - & $\begin{array}{c}\text { BZ in plane } \mathrm{CH} \\
\text { bend }\end{array}$ & 1458 & - & $\begin{array}{c}\text { BZ in plane } \\
\text { CH bend }\end{array}$ \\
\hline 1078 & - & $\begin{array}{c}\text { BZ in-plane CH } \\
\text { bend }\end{array}$ & 1427 & - & $\begin{array}{c}\text { BZ in-plane } \\
\text { CH bend }\end{array}$ \\
\hline 1034 & - & Thioamide III & 1324 & - & Thioamide III \\
\hline 783 & 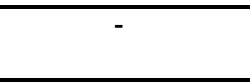 & BZ out-of-plane $\mathrm{CH}$ bend & 1288 & - & $\begin{array}{l}\text { BZ out-of-plane } \mathrm{CH} \\
\text { bend }\end{array}$ \\
\hline & - & & 1246 & - & \\
\hline & $1129,1119,1098$ & $\mathrm{ClO}_{4}^{-}$ & 1034 & $1129,1119,1098$ & $\mathrm{ClO}_{4}^{-}$ \\
\hline & 472 & $M-S$ & 758 & & \\
\hline
\end{tabular}




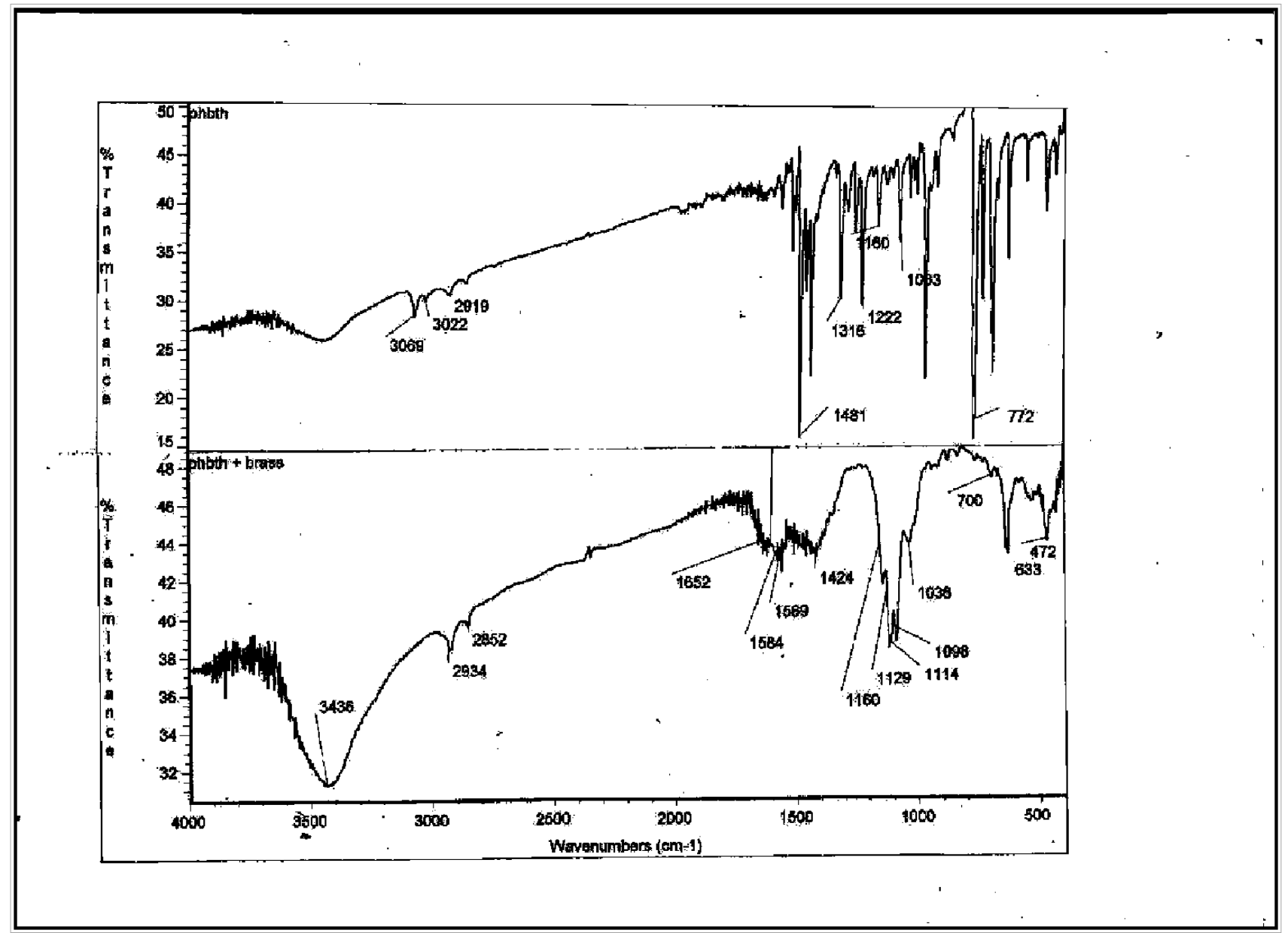

Fig. 4. Stacked IR spectra of PhBTH and PhBTH film on brass Table.

The IR data (Figure 4 and Table 6) show a significant shift in $\mathrm{C}=\mathrm{N}, \mathrm{C}-\mathrm{N}$ and $\mathrm{C}-\mathrm{S}$ stretching frequencies together with in-plane $\mathrm{C}-\mathrm{H}$ bending mode for the inhibitor-alloy films compared to that of the parent compounds suggesting that the inhibitors are chemisorbed on the brass surface through a co-ordinate type of linkage between lone pair of electrons on heteroatoms of inhibitor and the alloy. The structures of inhibitors are given below:

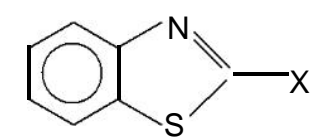

$X=$ H, BTH. $X=\mathrm{CH}_{3}$, MeBTH. $X=\mathrm{NH}_{2}, \quad$ ABTH. $X=\mathrm{C}_{6} \mathrm{H}_{5}$, PhBTH. X $=\mathrm{SH}, \mathrm{MBTH}$

Benzothiazole has two heteroatoms $\mathrm{N}$ and $\mathrm{S}$ in the thiazole ring. These 
heteroatoms have an ability to coordinate with transition metals like $\mathrm{Cu}$ and $\mathrm{Zn}$ or their alloys via the d-orbitals of the metals and empty p- or d-orbitals of heteroatoms in the inhibitor molecules $[31,32]$. In addition the р-л orbitals of the benzene ring can overlap with the metal d-orbitals leading to bond formation. A considerable shift observed in $\mathrm{C}=\mathrm{N}$ and $\mathrm{C}-\mathrm{S}$ stretching frequencies in the IR spectra (as well as the frequencies in the benzene ring) for the inhibitor-alloy film compared to those for pure compounds (Table 6) confirm that the BTH is chemisorbed on the surface through these links.

As BTH is believed to be anchored to the surface through the $\mathrm{N}$ and $\mathrm{S}$ at either end of the thiazole ring, the л - overlap of the benzene ring is favoured and the inhibitor is probably adsorbed flat onto the surface. This may perhaps be the reason why a moderate inhibitor efficiency (40\%) obtained at as low a concentration as $10^{-5} \mathrm{M}$ of the inhibitor.

The relatively enhanced inhibitor efficiency obtained with MeBTH may be attributed to the inductive effect of the $\mathrm{CH}_{3}$ group [33] at position 2 in the thiazole ring which enhances the electron density at the heteroatoms and thereby facilitate stronger bonds with the alloy surface leading to firmer adsorption. This is supported by a larger shift in $\mathbf{v}_{\mathrm{C}=\mathrm{N}}$ and $\mathbf{v}_{\mathrm{C}-\mathrm{S}}$ observed in the IR in case of MeBTH alloy films compared to that of BTH alloy film.

In the case of ABTH the lone pair of electrons of the "N" atom of the amino group attached to the thiazole ring provides an additional anchoring site for the inhibitor to bind with the metal surface thereby increasing the strength of adsorption and hence the inhibition. The evidence for this is provided by the shift in $\mathrm{N}-\mathrm{H}$ group frequency in addition to that of $\mathrm{C}=\mathrm{N}$ and $\mathrm{C}-\mathrm{S}$ in the $\mathrm{ABTH}$ film compared to that of ABTH parent compound.

While the introduction of $\mathrm{CH}_{3}$ in MeBTH and $\mathrm{NH}_{2}$ in ABTH contribute slightly to the size of the thiazoles, the introduction of a phenyl group in PhBTH adds considerably to the bulkiness of the inhibitor. This is the reason why the inhibitor efficiency attained a maximum value at $10^{-4} \mathrm{M}$ inhibitor concentration. The phenyl group with its $\pi-$ system additionally contributes to the adsorption of inhibitor. As a result the inhibitor efficiency observed in presence of PhBTH exceeds that of BTH, MeBTH and ABTH.

The maximum inhibitor efficiency has been observed with MBTH. The $\mathrm{pK}_{\mathrm{a}}$ of MBTH is 6.93 [34]. In acidic solution it exists predominantly in the thione [35, 36] form. This is supported by the presence of a band at $3113 \mathrm{~cm}^{-1}$.

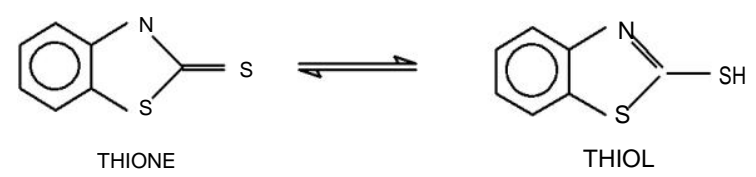

MBTH is known to form a thin polymeric film [37] on $\mathrm{Cu}$ forming a complex of the type $[\mathrm{Cu}(1) \mathrm{BTH}]_{\mathrm{n}}$ thus yielding high inhibitor efficiency [38].

The high inhibitor efficiency (90\%) obtained with MBTH during the corrosion of brass in $0.1 \mathrm{M} \mathrm{HClO}_{4}$ may also be attributed to a similar type of a thin polymeric complex film formed with $\mathrm{MBTH}$ and $\mathrm{Cu}(1)$ and $\mathrm{Zn}(1)$ species. The structure of the film may be written as: 
The formation of such a uniform and coherent film on the surface is therefore responsible for the high inhibitor efficiency observed.

The IR data show shift in the frequencies for the bands corresponding to Thioamide I, II, III [39]. The frequencies at $\approx 1566 \mathrm{~cm}^{-1}$ and $\approx 1432 \mathrm{~cm}^{-1}$ reported [40] for the conjugated $v_{\mathrm{C}=\mathrm{N}}$ and $v_{\mathrm{C}=\mathrm{C}}$ system are either absent or shifted in the films formed on metals (Table 6).

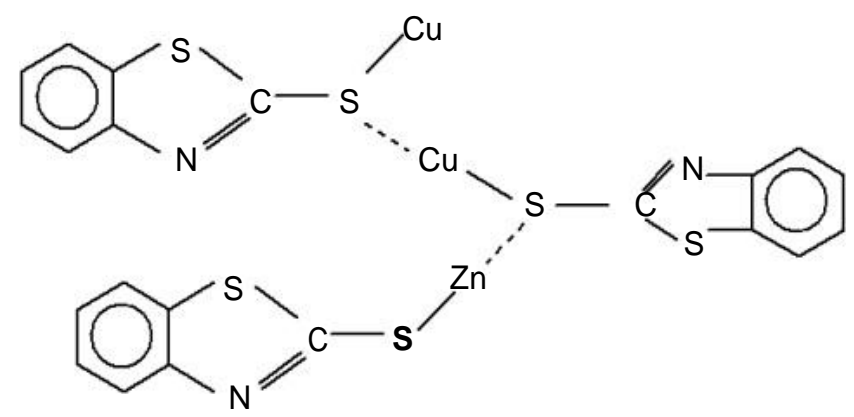

The presence of frequencies corresponding to M-S bond [41] at $\approx 465 \mathrm{~cm}^{-1}$ also support the complexation of inhibitors with metal surfaces.

The SEM Photographs of MeBTH and MBTH coated brass (Fig. $5 \mathrm{a}-\mathrm{d}$ ) show smooth surface with a fine texture compared to the rough surface of bare brass thus confirming the existence of the film. The energy dispersive X-ray analysis (EDAX) spectrum (Fig. 6) also substantiates the film formation and its chemisorption.
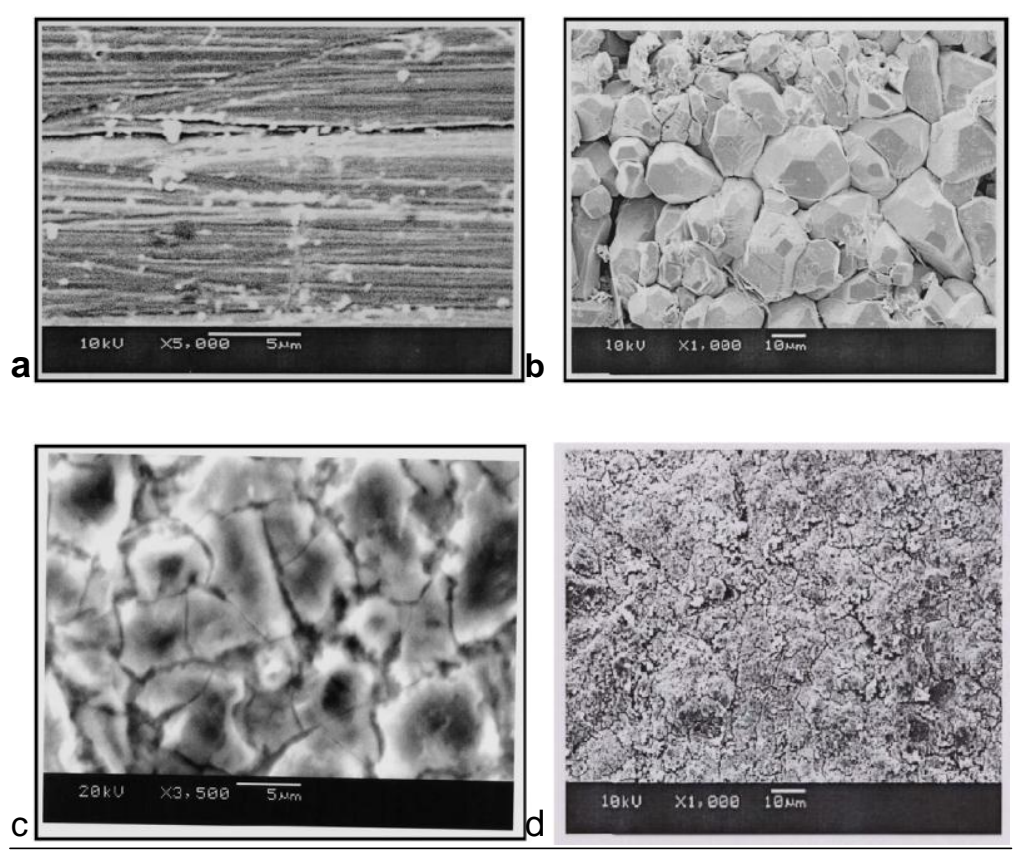

Figs. 5. a- polished brass surface, b- corroded surface, c- MeBTH film and d- MBTH film. 


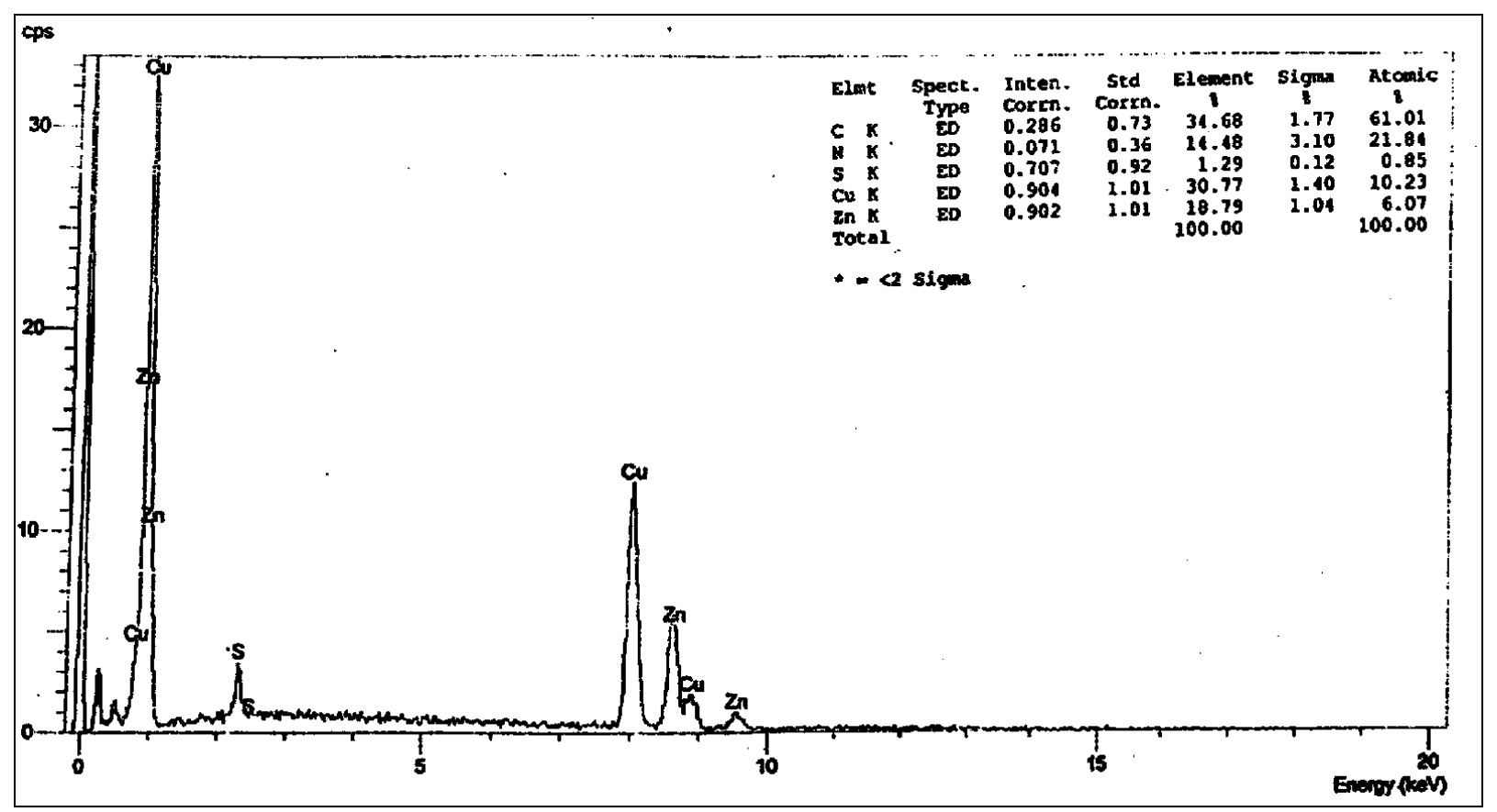

Fig. 6. EDAX spectrum of MBTH film on brass.

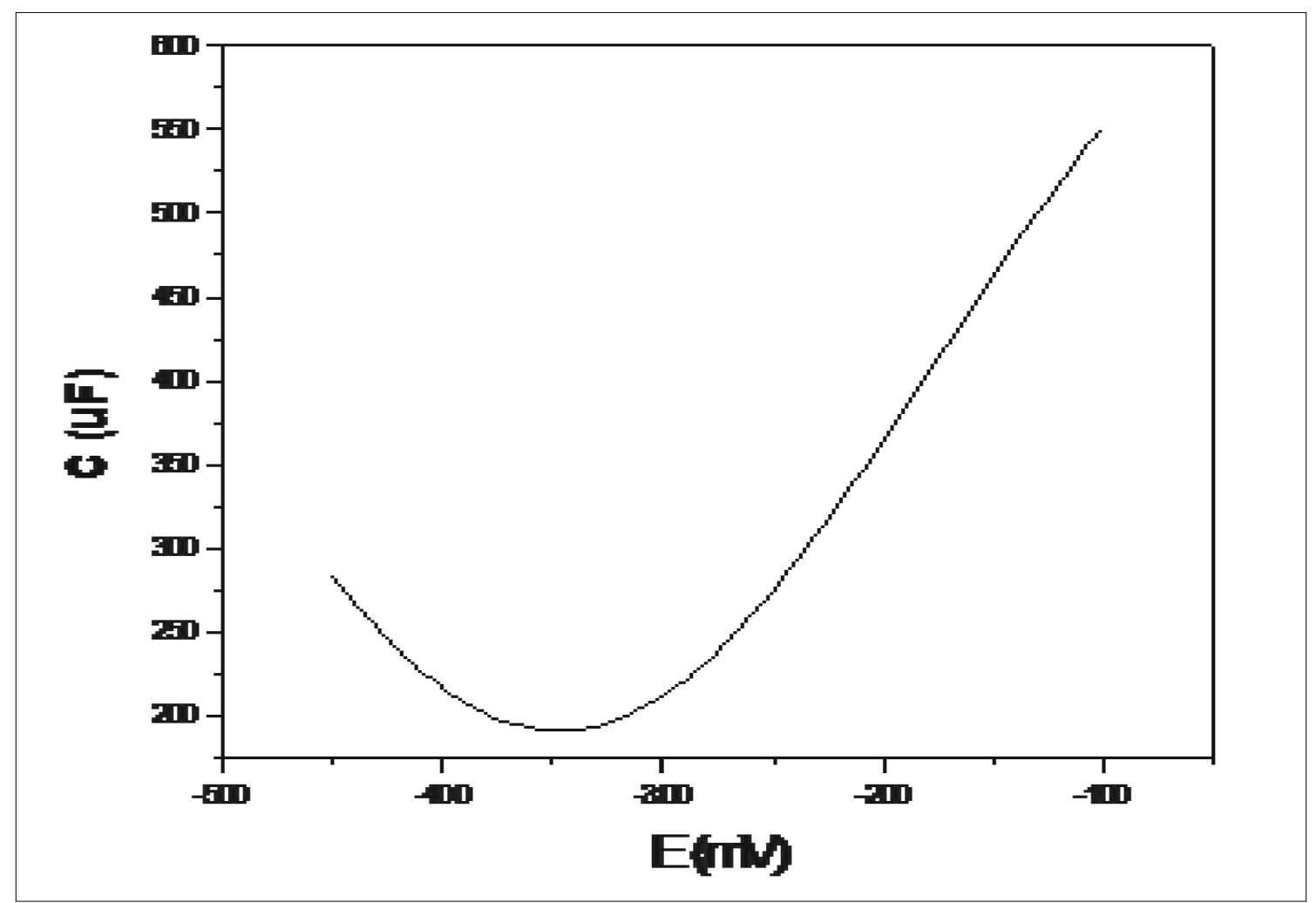

Fig. 7. Double layer capacitance vs applied potential for Brass in $0.10 \mathrm{M} \mathrm{HClO}_{4}$ 
The potential at zero current (PZC) value obtained by measuring the double layer capacitance of the electrode in at different potential (fig. 7) was found to be $-350 \mathrm{mV}$ indicating that the brass surface is negatively charged [42]. The inhibitor molecules which were protonated [12] by the acid can get electrostatically attracted to the negatively charged metal surface. This fact supports the efficiency of these inhibitors in protecting the brass corrosion.

\section{CONCLUSIONS}

Benzothiazole and substituted benzothiazoles offer inhibition by adsorption. They adsorb on the electrode surface obeying Freundlich adsorption isotherm. The distortion in the double layer structure due to this adsorption was found to be greater for $\mathrm{MBTH}>\mathrm{PhBTH}>$ $\mathrm{ABTH}>\mathrm{MeBTH}>\mathrm{BTH}$. The inhibitors chemisorbed on surface through coordinate type of bond between lone pair of electrons on heteroatoms.

Benzothiazoles anchor to the surface through the "N" and "S" at either side of the thiazole ring and the $\pi$-overlap of the benzene ring is favoured. With the introduction of - $\mathrm{CH}-$, $-\mathrm{NH}_{2}, \mathrm{C}_{6} \mathrm{H}_{5}$ - and $-\mathrm{SH}$ groups the molecule increased and the extent of adsorption increased. MBTH formed thin polymeric film and offer inhibition. The result obtained experimentally in this study agree exactly with the theoretical quantum mechanical calculations done for these compounds [43]

\section{References}

[1] S. L. Li, H. Y. Ma, S. B. Lei, R. Yu, S. H. Chen, D. X. Liu, Corrosion 54 (1998) 947-954.

[2] Vinicius C. Machado, Annelise M. Schmidt, Denise S. Azambuja, J. Braz. Chem. Soc. 11(4) (2000) 387-392.

[3] Gomma G. K., Wahdan M., Bull. Chem. Soc. Jpn. 67 (1994) 2621-2626.

[4] Hur E., Varol G. A., Gorgun K., Sakarya H., J. of Sci. 24 (4) (2011) 699707.

[5] Quraishi M. A., Khan M. A., Wajid Ajmal, M., Muralidharan S., Iyer S. Venkatakrishna, British Corrosion Journal 32(1) (1997) 72-76.

[6] Quraishi M. A., Wajid Khan M. A., Ajmal A., Muralidharan S., J. Appl. Electrochem. 26 (1996) 1253-1258 .

[7] Al-Mayouf A. M., Al-Suhybani A. A., Al-Ameery A. K., Desalination 116(1) (1998) 25-33.

[8] Quraishi M. A., Ahamed M. A. S., Venkatchari G., Bull. Electrochem. 13 (1997) $257-259$.

[9] Rafique M. Z. A., Khan S., Saxena N., Quraishi M. A., Electrochim. Acta 25 (4) (2007) 419-434.

[10] Antonijevic M. M., Petrovic M. B., A review. Int. J. Electrochem. Sci. 3 (2008) 1-28.

[11] Nandeesh L. S., Sheshadri B. S., Br. Corr. J. 23 (4) 91988) 239-244. 
[12] Rehan H. H., Material Science and Engineering Technology 24 (8) (1993) 304-308.

[13] Vastag Gy., Szocs E., Shaban A., Bertoti I., Popov-Pergal K., Kalman E., Solid State Ionics 141-142 (2001) 87-91.

[14] Ramji K., Cairns D. R., Rajeswari S., Appl. Surf Sci. 254 (2008) 4483-4493.

[15] Rawat J., Quraishi M. A., Corrosion 59(3) (2003) 238-241.

[16] Shanbhag A. V., Venkatesha T. V., Prabha A., Praveen B. M., Bull. Mater. Sci. 34(3) (2011) 571-576.

[17] Samar Y. Al-Nami, J. Mater. Environ. Sci. 4(1) (2013) 39-48.

[18] Osarolube E., Owate I. O., Oforka N. C., Scientific Research and Essay 3(6) (2008) 224-228.

[19] Fontana M. G., Stactile W., Corrosion Science and Technology, Plenum Press, London, 1 (1970) 149.

[20] Yurt A., Mihrican Y., Anti-Corros. Methods Mater. 55(4) (2008) 195-203.

[21] Quraishi M. A., Mideen A. S., Khan M. A. W., Ajmal M., Indian Journal of Chemical Technology 1 (1994) 329.

[22] Rosliza R., Wan Nik W. B., Curr. Appl. Phy. 10 (1) (2010) 221-229.

[23] Gao B., Zhang X., Sheng Y., Mater. Chem. Phys. 108(2-3) (2008) 375-381.

[24] Stern M., Geary A. J., Electrochem. Soc. 104 (1957) 56-63.

[25] Tebbji K., Oudda H., Hammouti B., Benkaddour M., Elkodadi M., Ramadani A., Colloids and surfaces physiochemical and engineering aspects 259 (1-3) (2005) 143-149.

[26] S. Muralidharan, K. L. N. Phani, S. Pitchumani, S. Ravichandran, S. V. K. Iyer, J. Electrochem. Soc. 142(5) (1995) 1478-1483.

[27] Juttner K., Electrochim. Acta 35 (10) (1997) 1501-1508.

[28] Mansfeld F., Electrochim. Acta 35 (10) (1990) 1533-1544.

[29] Franklin T. S., Rajesh A., Sheik Mideen A., Karthikeyan J., Anitha S., Indian Journal of Science and Technology 6 (2012) 1810-1815.

[30] Lece H. D., Kaan A., Emregtil C., Orhan A. Cotrrosion Sci. 5 (2008) 1460-1468.

[31] Loto R. T., Loto A. A., Popoola A A. P. I., J. Mater. Environ. Sci. 3(5) (2012) 885-894.

[32] Shahrabi T., H. Tavakholi, M. G. Hosseini, Anti-Corros. Methods Mater. 54 (2007) 308-313.

[33] Patel N. K., Makwana S. C., Patel M. M., Corr. Sci. 14 (1974) 91-94.

[34] Mantell A. E., Smith R. M., Critical Stability Constant, Plenum N.Y., 1997, vol. 3, p. 313. 
[35] Kumar S., Sankara Narayanan T. S. N., Suresh Kumar M., Manimaran M., International Journal of Electrochemical Science 1 (2006) 456-459.

[36] Oshawa M., Suetaka W., Corr. Sci. 19 (7) (1979) 709-722.

[37] Trabanelli G., Carassiti V., in Advances in Corrosion Science and Technology, 1, p. 147, Plenum Press, N.Y., 1970.

[38] Zhang D. Q., Gao L. X., Zhou G. D., Corrosion Science 46(12) (2004) 3031-3040.

[39] Rao C. N. R., Chemical Application of Infrared Spectroscopy, P-330, Academic Press, N.Y. (1963).

[40] Bellamy L. J., Advances in IR Group Frequencies, Chapman and Hall, London 1980.

[41] Motevalli M., O’Brien P., Walsh J. R., Watson I. M., Polyhedron 15 (1996) 801-808.

[42] Barsoukov E., Maodona J. R., Impedance Spectroscopy: Theory, Experiment and Application, J. Wiley \& Sons, 2005.

[43] Musa E. Mohamed, Kamal K. Taha, Nature and Science 9(8) (2011) 34-39. 